\title{
Agrotóxicos no Ensino de Ciếncias: uma pesquisa na educação do campo
}

Carolina dos Santos Fernandes' Geovana Mulinari Stuani'

'Universidade Federal de Santa Catarina (UFSC), Florianópolis/SC - Brasil

RESUMO - Agrotóxicos no Ensino de Ciências: uma pesquisa na educação do campo. Este trabalho tem como foco analisar e discutir as compreensões de estudantes do curso de Licenciatura em Educação do Campo da Universidade Federal de Santa Catarina (UFSC) a respeito da temática dos agrotóxicos no ensino de Ciências. Para apreensão das compreensões dos estudantes aplicou-se um instrumento em que os mesmos foram solicitados a discorrer a respeito da relevância de abordar a temática dos agrotóxicos na Educação Básica. A análise apontou a necessidade de entender a temática dos agrotóxicos em aspectos amplos que correspondem às dimensões teórico-metodológicas e conceituais, bem como econômicas, sociais, culturais, ambientais e éticas.

Palavras-chave: Educação do Campo. Ensino de Ciências. Agrotóxicos.

ABSTRACT - Pesticides in Science Education: the study in the field education. This work aims to analyze and discuss the students' understandings of undergraduate course in Field Education of the Federal University of Santa Catarina (UFSC) on the thematic of pesticides in science teaching. To grasp the understandings of students it was applied an instrument in which the undergraduates were asked to writer about the importance of addressing the issue of pesticide in basic education. The analysis pointed out the need to understand the thematic of pesticides on broad aspects that corresponds conceptual contents from the area of Natural Science and Mathematics, as well as social, environmental, political, economics, ethnical and others aspects.

Keywords: Field Education. Science Teaching. Pesticides.

Educação \& Realidade, Porto Alegre, v. 40, n. 3, p. 745-762, jul./set. 2015. 745 http://dx.doi.org/10.1590/2175-623645796 


\title{
Considerações Iniciais
}

O uso de agrotóxicos ${ }^{1}$ nas plantações de alimentos tem se mostrado um problema de ordem global e pouco problematizado nos meios de comunicação em massa, especialmente na educação formal, nos diferentes níveis em que atua.

A mídia televisiva e impressa argumenta que os agrotóxicos são prejudiciais à saúde humana, mas não aborda o problema a fundo, mascarando até mesmo a gravidade do uso de agrotóxicos nos alimentos. Portanto, cabe aos processos formativos problematizar essa temática que envolve questões não só de cunho conceitual, social, econômico, político, tanto de saúde pública e ambiental, quanto de segurança alimentar.

Percebe-se e se constata que a temática dos agrotóxicos ainda é pouco explorada no ensino. Por exemplo, na revista Química Nova na Escola existem apenas dois artigos com foco nos agrotóxicos, enquanto que das cinco coleções de livros didáticos de Química do Ensino Médio aprovadas na última avaliação do Plano Nacional do Livro Didático de 2012, apenas uma delas aborda de forma explícita a questão dos agrotóxicos. Portanto, se faz imperativa a abordagem dessa temática nos diferentes níveis de ensino, especialmente no ensino de Ciências.

A problemática do uso de agrotóxico tem se tornado cada vez mais preocupante, como relata uma reportagem publicada em setembro de 2012 na revista Ciência Hoje:

\begin{abstract}
O Brasil é a lixeira tóxica do planeta. Desde 2008, somos os maiores consumidores globais de insumos químicos para agricultura. Mas, diante de uma balança comercial envaidecida por números sedutores, discutir os reveses desse modelo agrário tornou-se tabu. A eterna e robusta economia agroexportadora, baseada em bens primários de baixo valor agregado, insiste em se reafirmar - ainda que assombrada por uma crise de percepção e acompanhada de temerosas dívidas sociais e ambientais (Kugler, 2012, p. 21).
\end{abstract}

De acordo com o autor supracitado, o problema do uso indiscriminado de agrotóxicos está relacionado com diferentes dimensões de difícil manejo. Com base no exposto, os agrotóxicos podem ser caracterizados como um problema de envergadura, isto é, atingem os sujeitos do campo enquanto produtores e consumidores e os sujeitos do meio urbano enquanto consumidores desses produtos. De acordo com Rigotto e Rosa (2012), diante do uso intenso dos agrotóxicos no Brasil, é possível considerar que a maior parte da população está exposta a esses produtos de alguma forma. As autoras ressaltam que os trabalhadores são os que primeiro sofrem, e por mais tempo, o efeito desses produtos. O segundo grupo seria formado pelas comunidades localizadas em torno de empreendimentos agrícolas ou industriais, e o terceiro pelos con- 
sumidores de alimentos contaminados, no qual se inclui praticamente toda a população.

Do mesmo modo, no que se refere ao balanço conflito/consenso, é certo que a temática dos agrotóxicos tem se caracterizado como um tema controverso, pois, de um lado, há os que defendem seu uso - de forma controlada - e sinalizam a inviabilidade de plantar em larga escala sem o uso desse defensivo, enquanto que, de outro, há os que apontam a possibilidade de plantar em larga escala sem a utilização dos agrotóxicos a partir de um novo modelo de desenvolvimento agrário.

Assim, o objetivo do presente trabalho centrou-se em analisar e discutir as compreensões de estudantes da Licenciatura em Educação da Universidade Federal de Santa Catarina (UFSC) a respeito da temática dos agrotóxicos no ensino de Ciências, bem como ressaltar a importância dessa abordagem na educação básica de escolas do campo, em áreas indígenas, quilombolas e urbanas.

\section{Cenário e Contexto da Investigação}

No segmento empírico desta investigação, foi realizado um estudo exploratório com licenciandos de uma das turmas do curso de Licenciatura em Educação do Campo da UFSC.

A primeira turma de licenciandos do curso ingressou em 2009 e, desde então, se realiza um vestibular anual para a entrada no curso, que tem como foco formar educadores para atuar em escolas do campo na área das Ciências da Natureza (Biologia, Química, Física) e Matemática. Cabe destacar que o curso é voltado àqueles que já possuem, no momento do ingresso, e em certo grau, alguma relação com o campo.

A Licenciatura em Educação do Campo apresenta uma forma de organização curricular diferenciada, isto é, o curso é estruturado, a partir de princípios da pedagogia da alternância e seus aportes metodológicos, os quais consistem em intercalar tempos universidade e tempos comunidade. Ou seja, os estudantes passam um período na universidade tendo aulas dos diferentes componentes curriculares que compõem o curso e, ao término deste, segue o tempo comunidade; quando se dirigem às localidades do campo para apreender dados desses municípios, que podem ser explorados durante os tempos universidade. É nesses municípios que os estudantes realizam seus estágios. Os estudos nas localidades são orientados por um roteiro de estudos e os dados apreendidos são discutidos pelos professores do curso, sendo que um dos problemas emergentes, nos diferentes municípios em que os estudantes realizam os tempos comunidade, é o uso de agrotóxicos.

De modo geral, o curso tem como proposta buscar romper com uma formação excessivamente fragmentada, apostando em um trabalho em que as diferentes áreas do conhecimento apareçam de forma integrada, como destacam Molina e Sá (2012):

Educação \& Realidade, Porto Alegre, v. 40, n. 3, p. 745-762, jul./set. 2015. 
[...] há que se destacar a intencionalidade maior da formação por área de conhecimento de contribuir com a construção de processos capazes de desencadear mudanças na lógica de utilização e de produção de conhecimento no campo. A ruptura com as tradicionais visões fragmentadas do processo de produção de conhecimento, com a disciplinarização da complexa realidade socioeconômica do meio rural na atualidade, é um dos desafios postos à Educação do Campo (Molina; Sá, 2012, p. 469).

Nessa direção, a temática dos agrotóxicos pode ser uma possibilidade para abordar conhecimentos das Ciências da Natureza e Matemática a fim de melhor compreender um problema social que abrange aspectos locais e globais, uma vez que toda a sociedade, de modo geral, tem sofrido com as consequências do uso indiscriminado de veneno nas plantações. Portanto, problematizar esta temática na formação inicial de professores pode ser uma possibilidade de abordagem contextualizada e analítica na educação básica.

\section{Caminhos Metodológicos}

Para apreender a compreensão dos licenciandos, aplicou-se um instrumento em que os mesmos foram solicitados a redigir um texto que contemplasse os seguintes aspectos: Discorra a respeito da relevância de abordar a temática dos agrotóxicos na educação básica. Igualmente descreva como você abordaria essa temática na educação básica de escolas do campo.

Foram analisados 12 textos identificados pela expressão licenciando e por uma letra do alfabeto com o intuito de preservar a identidade dos sujeitos. Estas produções textuais foram submetidas aos procedimentos da Análise Textual Discursiva - ATD -, que se caracteriza como um procedimento de análise de dados em que o material examinado é denominado de corpus (Moraes; Galiazzi, 2007). Este material pode ser produzido especialmente para a pesquisa ou por meio de materiais já existentes. A ATD é constituída de três etapas, a saber: unitarização, categorização e comunicação. Na unitarização, o corpus é fragmentado/desmontado em unidades de significado para a pesquisa, ou seja, neste trabalho as unidades de significado constituem fragmentos significativos das produções textuais dos licenciandos.

Já a categorização constitui a etapa em que as unidades de significado são agrupadas de acordo com critérios semânticos, enquanto que a comunicação caracteriza a última etapa em que são construídos os metatextos descritivos e/ou interpretativos, isto é, nesta etapa o pesquisador apresenta um novo olhar para o material analisado. Cabe destacar que a inserção de parte do corpus nos metatextos pode caracterizar uma forma de validar a análise (Moraes; Galiazzi, 2007). Igualmente, as unidades de significado expressas nas categorias são representativas, 
isto é, constituem um exemplar dos fragmentos que originaram as categorias. Os fragmentos contendo parte das produções textuais dos estudantes não foram alterados, mantendo-se, assim, a autoria das mesmas.

Na ATD não há a propriedade de exclusão mútua, ou seja, uma unidade de significado pode ser lida de diferentes formas, por isso uma mesma unidade de significado pode pertencer a mais de uma categoria ainda com significados distintos (Moraes; Galiazzi, 2007).

De acordo com os pressupostos da ATD, admitem-se três tipos de categorias: as categorias a priori, que já existem na literatura; as emergentes, que surgem a partir da análise dos dados; e as mistas, que congrega categorias a priori e emergentes. As categorias apresentadas neste trabalho são emergentes, quais sejam: Os agrotóxicos à luz de questões sociais; Agrotóxicos: causadores de problemas ambientais; e Como abordar a temática dos Agrotóxicos na Educação Básica.

\section{Os Agrotóxicos à Luz de Questões Sociais}

Ao se abordar os agrotóxicos à luz de questões sociais, surgem à tona outros aspectos de cunho econômico, político, cultural e de projeto de sociedade, intimamente inter-relacionados, em sua maioria, aos problemas sociais e de concepção de sociedade e desenvolvimento.

De modo geral, se disseminou que os agrotóxicos garantem o aumento na produtividade de alimentos (Veiga, 2007), mas esta aparente vantagem tem trazido sérios riscos ao ambiente e, por consequência, à saúde humana.

No âmbito do ensino de Ciências os agrotóxicos são vistos como um tema científico controverso, em razão das distintas visões sustentadas em relação às suas vantagens e desvantagens. Sendo, portanto, um produto do avanço científico e tecnológico, engloba na discussão relações entre Ciência, Tecnologia e Sociedade.

O movimento CTS - Ciência, Tecnologia e Sociedade - surgiu na década de 1960, na Europa e em países do Hemisfério Norte com a intenção de questionar a ideia de Ciência e Tecnologia como fontes absolutas de bem-estar social. O movimento CTS espalhou-se em distintas áreas de atuação, com destaque na área da educação, quando foi denominado de enfoque CTS. No Brasil, vários estudos discutem a inserção do enfoque CTS na educação, especialmente no ensino de Ciências (Auler; Delizoicov, 2006; Auler; Bazzo, 2001; Bazzo, 1998; Cruz; Zylbersztanjn, 2001; Pinheiro et al., 2007).

As principais contribuições do enfoque CTS dizem respeito à superação de construções históricas ligadas à Ciência e à Tecnologia, tais como: o determinismo tecnológico que defende que as mudanças sociais são exclusivamente decorrentes do desenvolvimento tecnológico; a visão salvacionista que outorga à Ciência e à Tecnologia a solução de problemas de diferentes ordens; e, por fim, a visão tecnocrata que

Educação \& Realidade, Porto Alegre, v. 40, n. 3, p. 745-762, jul./set. 2015. 749 
afirma que apenas especialistas podem tratar de Ciência e Tecnologia excluindo a sociedade de modo geral da tomada de decisões (Auler; Delizoicov, 2001).

A incorporação de conteúdos CTS no ensino pode gerar também a discussão das inter-relações CTS com implicações ambientais, denominada CTSA - Ciência-Tecnologia-Sociedade-Ambiente. Tanto o enfoque CTS quanto o CTSA visam à integração entre a educação científica, tecnológica e social, em que os conteúdos científicos e tecnológicos são estudados considerando-se aspectos históricos, éticos, políticos e socioeconômicos (López; Cerezo, 1996).

Nessa direção, ao analisarmos a compreensão dos licenciandos sobre a temática agrotóxicos, percebeu-se aproximações em seus relatos com o enfoque CTS, tal como descrevem:

Considerando as estatísticas atuais o Brasil é o maior consumidor mundial de agrotóxicos. A partir do modelo de agricultura modernizada a Revolução Verde, dissemina-se um grande incentivo e consumo sem controle e leis para o uso e manuseio dos mesmos (Licenciando B).

Essa forma de produzir alimentos surge com a revolução verde e se baseia no uso de agrotóxico, monocultura e uso de maquinário. Chega a solos brasileiros em meados da década de 60 e se concretiza como hegemônico na década de 70, trazendo junto nos pacotes, o endividamento de agricultores, a poluição de nossos solos, desertificando nossas terras, expulsando o homem do campo e trazendo doenças tanto para as pessoas do campo quanto para a cidade. Tudo isso acontece, pois algumas empresas contaminam e mantêm esses problemas (MONSANTO, SINGONTA, CARGIL entre outras). Essas empresas junto de alguns governos são os principais responsáveis por fazer isso funcionar, os agricultores de nosso campo desacreditam da vida no campo, estão doentes e seus filhos vendo como anda o trabalho na agricultura não querem continuar no campo (Licenciando $\mathrm{M}$ ).

Na década de 60 e 70 ocorreu no Brasil a chamada modernização da agricultura e com ela a introdução do capital na agricultura brasileira, que ocasionou modificações na estrutura agrária no Brasil. Entre as diversas transformações ocorridas no campo, destaca-se o início do processo de êxodo rural e a formação do proletariado agrícola (Licenciando G).

Nos fragmentos acima se percebe dois aspectos importantes intimamente relacionados: o primeiro diz respeito à transformação na vida do campo que leva o camponês a migrar para as cidades submetendo-se na maioria das vezes a trabalhos com condições precárias; o segundo, à chamada de atenção dos estudantes para a Revolução Verde, que modificou a estrutura agrária em muitos aspectos, adequando-a aos interesses do capital como destaca Leroy:

O modelo de agricultura dominante é oriundo do que se convencionou chamar de Revolução Verde, implementada a partir da segunda metade do século XX para incrementar a agricultura nos países ditos então subdesenvol- 
vidos. A Revolução Verde está calcada no uso combinado de variedades (sementes e matrizes) de alto rendimento, de adubos e produtos fitossanitários (os agrotóxicos) e na irrigação intensiva. Ela facilitou o crescimento da grande propriedade e, com ela, o uso de maquinário pesado. Com ela, efetivamente, aumentou enormemente a produção de alimentos, embora a fome continue, já que a alimentação se tornou uma mercadoria inacessível para muitos. Nota-se que os agrotóxicos fazem parte de um pacote. Se quisermos questioná-los, é preciso questionar o pacote inteiro (Leroy, s/d, p. 06).

Para se compreender as relações existentes entre a Ciência-Tecnologia-Sociedade, Silva (2004) chama a atenção para a importância do conhecimento social que coloca os problemas da Ciência envoltos em um contexto que engloba múltiplas relações de construção, fragmentação e reconstrução das ações e organizações humanas. Além do conhecimento ético que nega a neutralidade científica, o autor defende que o conhecimento deve ser comprometido com o contexto de sua aplicação (dimensão prática) e implicações (dimensão ética). Assim, na perspectiva do enfoque ético, através da interação, a sociedade é chamada a participar com o poder de influenciar a natureza, os rumos e as prioridades da tecnociência que mais lhe interessam (Silva, 2004).

Essa preocupação em discutir o tema na dimensão social e ética constitui a compreensão dos graduandos da Licenciatura em Educação do Campo:

O uso de agrotóxico deveria ser conteúdo tanto de escolas do campo quanto para os que ficam nos centros urbanos. Pois as consequências do uso desses produtos atingem tanto a população do campo quanto da cidade, consumidor desse produto. No campo ou nas escolas do campo esse tema deveria ser tratado de certeza, com mais importância, é no campo que se pulveriza os agrotóxicos e é no campo que se produz a comida para toda a população, seja ela rural ou urbana (Licenciando M).

Nas vivências de campo podemos perceber que os povos estão adoecendo pelas novas doenças do séc. XXI como câncer, depressão profunda entre outras. Talvez por falta de informação, mas principalmente pela maldade das multinacionais que os fabricam e a ignorância do governo que as lideram. Temos que através da educação combater este massacre invisível ao povo brasileiro que em doses homeopáticas estão morrendo pela boca (Licenciando $\mathrm{H}$ ).

Na percepção desses futuros professores, os agrotóxicos constituem um problema social interligado a aspectos políticos. Sabe-se que existe uma pressão feita por lideranças políticas à ANVISA (Agência Nacional de Vigilância Sanitária) ao questionar resoluções que vetam, por exemplo, a comercialização e o uso de agrotóxicos com substâncias não permitidas por tal agência. Soma-se a isto o fato de que muitas empresas produtoras de agrotóxicos são/podem ser financiadoras de campanhas políticas. Com base no exposto, Leroy argumenta: 
Isso não seria possível sem uma combinação de interesses que junta as grandes corporações, os principais meios de comunicação e a grande maioria dos executivos e legisladores. Ao seu serviço, os economistas, que mostram que o agronegócio exportador, e a tecnociência já mencionada, é a salvação do país. Esse conjunto faz o que eles identificam como sendo a opinião pública acreditar que a modernidade, o desenvolvimento do país e a erradicação da miséria passam por esse modelo de agricultura. Em retorno, empresas, partidos e políticos e meios de comunicação se apoiam nessa opinião pública que formaram para impor seus interesses como se fossem os interesses de todos. $\mathrm{O}$ círculo vicioso se fecha. As outras falas são silenciadas e passam a não existir (Leroy, s/d, p. 08).

Percebe-se, nessa direção, também que os licenciandos compreendem os agrotóxicos a partir de uma perspectiva crítica e social, o que implica relacionar essas visões à importância do acesso à Alfabetização Científica Ampliada (Auler; Delizoicov, 2001) que, baseada em Freire (1987; 1998), concebe o conhecimento científico como um desvelar de problemas sociais. Auler e Delizoicov (2001) entendem a Alfabetização Científica Ampliada - apoiada na perspectiva freireana de educação como a busca por uma educação problematizadora e dialógica na compreensão das interações entre Ciência, Tecnologia e Sociedade, e na elaboração do conhecimento no intuito de superar a visão fatalista, neutra e ingênua de Ciência e Tecnologia.

As concepções dos estudantes da Licenciatura em Educação do campo aproximam-se dessa perspectiva de Alfabetização Científica quando defendem que:

Com a introdução ao capitalismo no campo brasileiro, há a necessidade de produzir mais em um mesmo tempo [...] há a necessidade de alimentar toda a população brasileira. Dessa forma, fomos inseridos mesmo que sem querer, em um novo padrão alimentar, onde nos alimentamos de comidas industrializadas e com altíssimas quantidades de produtos tóxicos, ou seja, estamos comendo veneno diariamente. Sendo assim, não nos damos conta de que desta forma estamos nos envenenando, ainda mais, pois os alimentos que são mais saudáveis são os produtos orgânicos, cujo preço não cabe em nosso bolso (Licenciando G).

[...] a falta de informação a qual vive a população, sem acesso, vivendo no contexto de massificação, pobre e sem poder de compra fica submetida ao consumo de alimentos com veneno (Licenciando B).

Ao analisar as visões dos acadêmicos, percebe-se que a perspectiva de educação que defendem, quando se referem ao problema dos agrotóxicos, aproxima-se da perspectiva progressista e crítica (Snyders, 1974; Freire, 2008), uma vez que concebem a temática em uma perspectiva social. Salienta-se também uma proximidade das ideias dos acadêmicos com a Teoria Crítica formulada pelos pensadores alemães da Escola de Frankfurt ${ }^{2}$, como Max Horkheimer e Theodor Adorno. Esta 
teoria critica a sociedade industrial cujas implicações ideológicas pautam-se na massificação da produção cultural e na formação da consciência social (Fabiano; Silva, 2012). Entretanto, visto a influência das lutas sociais no campo na organização da Educação do Campo, considera-se que os acadêmicos poderiam argumentar mais explicitamente quanto às alternativas para combater ou diminuir o uso de agrotóxicos na produção de alimentos. Igualmente, notamos uma ausência nos textos dos licenciandos do papel dos movimentos sociais na problematização do uso de agrotóxicos.

\section{Os Agrotóxicos: causadores de problemas ambientais}

Os agrotóxicos têm sido utilizados há bastante tempo por agricultores no combate a pragas que afetam a produção de alimentos. Porém, seus efeitos não se restringem às pragas, podendo causar sérios danos ao ambiente e à saúde humana (Miranda et al., 2007). De modo que, quando nos referimos ao ambiente, incluímos igualmente o ser humano como parte integrante do meio ambiente, uma vez que entendemos que os danos à saúde humana, causados pelos agrotóxicos, são também problemas ambientais.

Com o intuito de minimizar as consequências negativas do uso de agrotóxicos, a ANVISA foi criada com o objetivo de promover a saúde através da ingestão de alimentos saudáveis e prevenção de doenças crônicas não transmissíveis - DCNT -, oriundas da ingestão cotidiana de doses perigosas de agrotóxicos (ANVISA, 2010). Estima-se que no Brasil as DCNT teriam causado 893.900 mortes em 2008, responsável por $74 \%$ das mortes ocorridas naquele ano (ANVISA, 2010).

Em virtude do aumento dos casos de intoxicação pelo uso de agrotóxicos por agricultores rurais, estudos e pesquisas têm sido desenvolvidos (Guivant, 1994; Moreira et al., 2002; Faria et al., 2000; Gomide, 2005; Araújo et al., 2007) com a intenção de investigar as principais causas das intoxicações e as compreensões dos agricultores sobre o tema, além de tentar entender a forma de uso desses defensivos agrícolas.

Podemos considerar, então, que esse problema, por ultrapassar as questões individuais, torna-se um problema ambiental e consequentemente de saúde pública (WHO, 1990), já que a produção de alimentos interfere tanto na saúde humana quanto no saneamento ambiental. Estas questões estão presentes nas visões apresentadas pelos licenciandos, representada no fragmento abaixo:

[...] os estudos atuais nos relatam o alto índice de intoxicações e óbitos [...]. Neste sentido, chama a atenção, para os óbitos e suicídios elevadíssimos, com base na depressão que esses produtos produzem no ser humano (Licenciando B).

No processo de intoxicação pelo uso de agrotóxicos, Miranda et al. (2007) destacam os vários fatores intervenientes como: o desconhe- 
cimento quanto aos riscos à saúde associado ao desrespeito quanto às normas básicas de segurança, a livre comercialização, a grande pressão comercial por parte das grandes empresas distribuidoras e produtoras de agrotóxico, além dos problemas sociais encontrados no meio rural.

Devido à contaminação ambiental e aos resíduos de agrotóxicos nos alimentos, podemos também estimar que as populações residentes próximo a áreas de cultivo e os moradores urbanos também estão significativamente expostos aos efeitos nocivos destes agentes químicos (Miranda et al., 2007, p. 11-12).

A consciência crítica sobre os fatores que interferem na contaminação ambiental pelo uso dos agrotóxicos apareceu nos seguintes relatos:

Por ser um dos produtos mais utilizados [...] tanto nas lavouras de milho, soja, fumo, etc. e até nas plantações de verduras e frutas, nas pequenas propriedades. Sabendo que a maioria deles (referindo-se aos agricultores) não usam os equipamentos obrigatórios para o manuseio das embalagens e até mesmo na hora de passar os produtos nas plantas, sendo que alguns ainda lavam as embalagens e jogam o produto próximo a poços artesianos e até mesmo utilizam embalagens para plantar ou reutilizam para guardar outros produtos (Licenciando I).

[...] outro fator agravante é que esses venenos param na mesa da população brasileira e mundial. A grande maioria dos grãos e dos produtos hortifrutigranjeiros estão contaminados, colocando assim em risco a saúde de nossa população (Licenciando B).

A contaminação ambiental provocada pelos agrotóxicos tem causado forte impacto sobre a população de animais e plantas, além da contaminação de coleções de águas superficiais e subterrâneas, conforme apontam Peres et al. (2003). Os autores reiteram também os riscos dos agrotóxicos à saúde das populações e ao meio ambiente, sendo seu uso restrito a casos absolutamente imprescindíveis. Os licenciandos, por sua vez, demonstraram a mesma preocupação dos autores citados com relação à preservação do meio ambiente e à qualidade de vida, como destaca um dos investigados: os danos que o agrotóxico pode causar tanto à nossa saúde quanto ao meio ambiente podem ser explicados $\mathrm{e}$ comprovados através de estudos científicos já realizados nessas áreas específicas (E).

A situação da agricultura brasileira não está desvinculada da conjuntura econômica mundial, pautada na lógica do neoliberalismo, com o incentivo à agroindústria de exportação baseada, sobretudo, na monocultura, no latifúndio e no agronegócio com o aumento da produtividade pela introdução de novas tecnologias de produção e de agentes químicos (Miranda et al., 2007). Esta concepção está presente no seguinte relato: 
Nesta perspectiva pensar que nos encontramos num beco sem saída. De um lado a força do agronegócio instalado atualmente no Brasil, colocando o país como O celeiro mundial, impactando o solo a partir de práticas de monocultura agro-exportadora o que vem comprometer os lençóis freáticos com a grande demanda de agrotóxicos (Licenciando B).

A reversão desta situação, com a minimização dos impactos dos agrotóxicos ao ambiente, envolve medidas a curto e longo prazo, com a melhoria das condições de produção dada aos pequenos agricultores e com uma assistência técnica adequada e suficiente a tais grupos (Miranda et al., 2007). Outra medida refere-se a uma melhor nutrição das plantas como uma proteção contra as pragas (Ghini; Bettiol, 2000).

Assim, ao analisar as compreensões dos licenciandos com relação aos agrotóxicos como causadores de problemas ambientais, percebe-se um modelo baseado na busca por uma produção de alimentos menos agressiva, conforme destacado pelos licenciandos nos fragmentos supracitados. Apesar de não explicitarem nitidamente em seus relatos a produção agroecológica, esta aparece como pano de fundo em suas falas, quando censuram o uso de agrotóxicos. Nota-se igualmente uma visão crítica e atualizada com as pesquisas da área, porém, não propõem alternativas concretas para o problema. Outro aspecto que chama atenção é a visão antropocêntrica apresentada pelos futuros professores que separam os problemas ambientais dos problemas de saúde da população, de modo geral, com o uso de agrotóxicos. Cabe destacar que as doenças e a fome, por exemplo, também são considerados problemas ambientais e políticos em uma perspectiva mais ampla.

\section{Como Abordar a Temática dos Agrotóxicos na Educação Básica}

Outra categoria que emergiu das produções textuais dos licenciandos concerne às possibilidades de abordar a temática dos agrotóxicos na educação básica, tanto em escolas do campo quanto em áreas urbanas, indignas e quilombolas. Em razão da ampla utilização dos agrotóxicos na atualidade, esta temática se tornou cada vez mais pertinente de ser tratada na educação básica, como é destacado:

O agrotóxico está sendo um tema muito discutido atualmente, mas nas escolas nem sempre é colocado em debate, e quando é, é muito sintético (Licenciando L).

Embora o licenciando aponte que a temática dos agrotóxicos tem sido bastante discutida, diz que na escola o tema é ainda incipiente, sinalizando, assim, a necessidade de sua abordagem nos processos formativos, de modo sistemático. E apesar de não se mencionar em que lugar essa discussão está ocorrendo, acredita-se que possa ser nos meios de comunicação, não obstante tais meios apresentam suas matérias de forma comumente unilateral. De todo modo, a fala do licenciando é 
fortalecida quando analisamos os livros didáticos da educação básica, conforme destacado na introdução deste trabalho. O fato da problemática dos agrotóxicos apresentar controvérsias pode ser um indicativo das dificuldades dos professores sobre como devem tratar o assunto em sala de aula.

Cabe destacar que das cinco coleções de Química aprovadas no Plano Nacional do Livro Didático de 2012 para o Ensino Médio apenas uma aborda de forma explicita a temática dos agrotóxicos trazendo como foco aspectos conceituais da Química como a classificação dos agrotóxicos, grupo químico a qual pertence além da classificação toxicológica dos agrotóxicos de acordo com a ANVISA. Do mesmo modo, tal coleção aborda aspectos ligados à agricultura orgânica e familiar apontando para uma forma de diminuir ou eliminar o uso de agrotóxico nas lavouras.

Os licenciandos mencionam também que a temática dos agrotóxicos pode ser desenvolvida a partir de diferentes olhares disciplinares, como bem destacam:

A temática agrotóxico pode ser trabalhada de diversas formas, desde sua elaboração até a sua utilização e efeitos. Na disciplina de Química pode ser trabalhada sua composição e quais elementos químicos são utilizados. Na biologia sua utilização nas plantações, seus efeitos nas plantas (sua absorção) e seus efeitos no organismo humano (Licenciando K).

No dia a dia das disciplinas, como Química, por exemplo, examinado o solo contaminado em relação a outro não contaminado, que elementos químicos existem ali. Na matemática calcular a percentagem de veneno ou proteínas e vitaminas. Também poderíamos calcular o que precisamos para converter o sistema tradicional da agricultura para um agroecossistema florestal super possível e sustentável. Em temas como este poderíamos estudar de forma integrada todos os ciclos da vida o que é primordial para que possamos entender a nós mesmos (Licenciando $\mathrm{H}$ ) (Grifo nosso).

Nos fragmentos acima os estudantes apontam, mesmo que timidamente, conteúdos disciplinares que podem ser trabalhos a fim de melhor entender os agrotóxicos, ou seja, o tema pode ser analisado por diferentes áreas do conhecimento. De certa forma, os licenciandos parecem aproximar-se de uma metodologia de ensino em consonância com a abordagem temática, embora não o explicitem claramente. $\mathrm{Na}$ abordagem temática ${ }^{3}$, a organização curricular é estruturada com base em temas, mediante os quais são selecionados os conteúdos de ensino das diferentes disciplinas, isto é, a conceituação científica é subordinada ao tema (Delizoicov; Angotti; Pernambuco, 2002).

O fato dos estudantes compreenderem que a temática dos agrotóxicos possa ser analisada por diferentes olhares disciplinares possibilita, em certa medida, uma abordagem interdisciplinar favorecida pela abordagem temática. Este aspecto merece destaque, uma vez que parece tentar romper com abordagens puramente conceituais em que 
problemas locais e globais parecem ser pouco explorados no processo de ensino e aprendizagem.

Os licenciandos também apontaram a necessidade de apreender as concepções iniciais dos educandos no processo de ensino e aprendizagem, conforme destacado:

Levantar o conhecimento prévio dos estudantes com questões como: o que são agrotóxicos? Você conhece algum defensivo agrícola? Quais efeitos dos produtos dos agrotóxicos à saúde? Que ações poderiam ser desenvolvidas para que houvesse a redução do uso de agrotóxicos em sua comunidade? Se os conteúdos abordados estão relacionados a fatos ou causas do dia a dia? Alguma outra vez este tema agrotóxico já foi abordado em sala de aula? (Licenciando J).

Embora o licenciando não discorra como trabalharia com as concepções iniciais dos estudantes, merece destaque o fato de levar em consideração tal aspecto, que se assemelha, em certa medida, à ideia de problematização (Freire, 2008), na qual se busca a ruptura do conhecimento de senso comum dos estudantes acerca da realidade. Neste caso, conhecer melhor as consequências do uso dos agrotóxicos para a sociedade pode ser uma forma de possibilitar a transformação da realidade, mesmo que a temática seja de difícil trato.

Outro aspecto salientado pelos estudantes como algo fundamental para ser ensinado aos estudantes da Educação Básica de escolas do campo refere-se os cuidados na utilização dos agrotóxicos:

O interessante é conscientizar os alunos sobre o uso correto de agrotóxicos, seus males, desenvolvendo o senso crítico para que eles façam suas escolhas. Pois não devemos somente desprezar e crucificar o uso de agrotóxicos, pois esta é uma realidade existente na maioria das propriedades (Licenciando D).

A ressalva pela utilização de forma adequada dos materiais e roupas de segurança no momento da aplicação do veneno nas lavouras permeou a fala dos licenciandos. Esta chamada de atenção se faz imperativa, pois muitos dos estudantes de escolas do campo são produtores ou filhos de produtores, de modo que saber usar corretamente os materiais de segurança pode auxiliar na prevenção de acidentes. No entanto, é preciso tomar cuidado para não reduzir o problema dos agrotóxicos apenas à falta e/ou inadequação de equipamentos de segurança durante a aplicação do veneno.

As possíveis tensões em discutir os efeitos indesejáveis do uso de agrotóxicos foram igualmente salientadas:

A diferença de trabalhar este conteúdo nas escolas do campo e nas da cidade, é que no campo os alunos já têm uma proximidade maior com os agrotóxicos, principalmente quando a família o utiliza nos cultivos. Então a facilidade de entrar com o tema em sala de aula é maior, porém não descartando a hipótese de que pode ser mais difícil trabalhar com 
as consequências negativas resultados da utilização dos agrotóxicos, a aceitação por parte dos alunos que tem convivência com este pode não haver (Licenciando K).

A possível compreensão que o uso de agrotóxico para combater pragas é um dos responsáveis pelo aumento da produção de alimentos e consequentemente do aumento da renda familiar do agricultor pode gerar dificuldades na aceitação dos estudantes acerca dos efeitos negativos oriundos da utilização desses defensivos agrícolas. No entanto, mesmo frente a novas dificuldades, a abordagem de tal temática é de fundamental importância.

Em síntese, a exploração da temática dos agrotóxicos pode ser uma possibilidade profícua de abordar, de forma integrada, conteúdos de diferentes áreas do conhecimento, permitindo, assim, uma compreensão mais ampla da realidade indo ao encontro da proposta dos cursos de Licenciatura em Educação do Campo, a saber, uma formação em que as diferentes áreas do conhecimento dialoguem com intuito de compreender problemas vinculados a realidade dos estudantes. Por fim, salienta-se a necessidade dos processos educativos formais abordarem a problemática dos agrotóxicos a fim de formarem professores mais conscientes dos problemas sociais da atualidade, além de vislumbrar práticas educativas para além do espaço escolar, essas possíveis para articular transformações para a realidade vigente.

\section{Considerações Finais}

Com base nas categorias de análise foi possível compreender que a temática dos agrotóxicos pode ser discutida em diferentes níveis de ensino e por diferentes áreas do conhecimento. No ensino de Ciências podem ser explorados aspectos ligados a conteúdos conceituais e de cunho social, ambiental, político, econômico, histórico e ético, como também outros igualmente importantes para a formação de professores mais críticos e ativos na sociedade.

Do mesmo modo, os agrotóxicos podem ser analisados por diferentes lentes teóricas e metodológicas, como por exemplo, o enfoque CTS, a educação ambiental e referenciais ligados à perspectiva freireana de educação e outras perspectivas analíticas críticas, como a Marxista.

Embora os licenciandos tenham apresentado uma visão contundente oposta aos agrotóxicos, esta não é a concepção que permeia a sociedade de modo geral, uma vez que a ideologia do projeto de modernidade capitalista é estendida e divulgada nos meios e comunicação e também na formação escolar como se fosse o modelo que expressa apenas impactos positivos e universais a população. Assim sendo, os agrotóxicos podem ser considerados um tema social e científico controverso, e como tal, esconde e omite suas contradições, sendo que é preciso, no espaço formativo, abordar as distintas visões, contextualizá-las e apre- 
ender suas apropriações e finalidades a respeito do tema. De acordo com Reis, a discussão de questões controversas em sala de aula é "[...] extremamente útil quer na aprendizagem dos conteúdos, dos processos e da natureza da ciência e da tecnologia, quer no desenvolvimento cognitivo, social, político, moral e ético dos alunos” (Reis, 2007, p. 50). $\mathrm{O}$ autor argumenta ainda que em uma sociedade democrática a avaliação pública da ciência defende que os sujeitos devem ser capazes de reconhecer o que está envolvido em uma controvérsia a fim de alcançar uma opinião informada e participar de processos de tomada de decisão (Reis, 2007). Portanto, a abordagem da temática agrotóxicos no ensino de ciências pode desencadear de processos formativos que desenvolvam nos estudantes a capacidade de argumentação e poder de decisão, análise e posicionamento crítico e prática social diante de temas que interferem em suas vidas.

Recebido em 20 de março de 2014 Aprovado em 09 de outubro de 2014

\section{Notas}

1 De acordo com a Lei $\mathrm{N}^{\circ} 7.802$ agrotóxicos são “[...] produtos e agentes de processos físicos, químicos ou biológicos para uso no cultivo, armazenamento e beneficiamento de produtos agrícolas, para alterar a composição da flora ou da fauna, a fim de preservá-las da ação de seres vivos nocivos” (Brasil, 1989).

2 A Escola de Frankfurt refere-se a um grupo de intelectuais que compunham o Instituto de Pesquisa Social em Frankfurt, fundado em 1911 por Carl Grünberg. Estes pensadores buscavam analisar a sociedade, tecendo fortes críticas a indústria cultural (Mogendorff, 2012).

3 Os educadores Paulo Freire e George Snyders propõem um ensino pautado em temas, isto é, uma abordagem temática em que são levados em conta, na programação curricular e no planejamento didático-pedagógico, duas categorias, a saber: o conhecimento científico e o senso comum, este último estando presente no conhecimento prévio dos estudantes e que busca ser rompido no processo de formação (Delizoicov; Angotti; Pernambuco, 2002).

\section{Referências}

AGÊNCIA NACIONAL DE VIGILÂNCIA SANITÁRIA (ANVISA). Programa de Análise de Resíduos de Agrotóxicos em Alimentos: relatório de atividades 2010. Disponível em: <http://www.anvisa.gov.br>. Acesso em: 21 jan. 2013.

ARAÚJO, Alberto José de et al. Exposição Múltipla a Agrotóxicos e Efeitos à Saúde: estudo transversal em amostra de 102 trabalhadores rurais, Nova Friburgo/ RJ. Revista Ciência e Saúde Coletiva, Manguinhos/RJ, Associação Brasileira de Pós-Graduação em Saúde Coletiva, v. 12, n. 1, p. 115-130, 2007.

AULER, Décio; BAZZO, Walter Antonio. Reflexões para a Implementação do Movimento CTS no Contexto Educacional Brasileiro. Revista Ciência \& Educação, Bauru/SP, Programa de Pós-Graduação em Educação para a Ciência- UNESP, v. 7, n. 1, p. 1-13, 2001. 
AULER, Décio; DELIZOICOV, Demétrio. Alfabetização Científico-Tecnológica para quê? Ensaio, Belo Horizonte, Faculdade de Educação da UFMG, v. 3, n. 1, p. 1-13, 2001.

AULER, Décio; DELIZOICOV, Demétrio. Educação CTS: articulação entre pressupostos do educador brasileiro Paulo Freire e referenciais ligados ao movimento CTS. In: O ENCONTRO IBEROAMERICANO SOBRE LAS RELACIONES CTS EN LA EDUCACIÓN CIENTÍFICA, 5, 2006, Málaga. Anais... Málaga: Editora da Universidade de Málaga, jul. 2006. P. 1-9.

BAZZO, Walter Antonio. Ciência, Tecnologia e Sociedade: e o contexto da educação tecnológica. Florianópolis: Ed. da UFSC, 1998.

BRASIL. Lei 7.802/1989. Dispõe sobre a Pesquisa, a Experimentação, a Produção, a Embalagem e Rotulagem, o Transporte, o Armazenamento, a Comercialização, a Propaganda Comercial, a Utilização, a Importação, a Exportação, o Destino Final dos Resíduos e Embalagens, o Registro, a Classificação, o Controle, a Inspeção e a Fiscalização, de Agrotóxicos, seus Componentes, e Afins, e dá outras providências. Diário Oficial da União, Brasília, 12 jul. 1989. P. 11459.

CRUZ, Sônia Maria Silva Côrrea de Souza; ZYLBERSZTAJN, Arden. O Enfoque Ciência, Tecnologia e Sociedade e a Aprendizagem Centrada em Eventos. In: PIETROCOLA, Maurício (Org.). Ensino de Física: conteúdo, metodologia e epistemologia numa concepção integradora. Florianópolis: Ed. da UFSC, 2001. P. 171-196.

DELIZOICOV, Demétrio; ANGOTTI, André Jose; PERNAMBUCO, Marta Maria. Ensino de Ciências: fundamentos e métodos. São Paulo: Ed. Cortez, 2002.

FABIANO, Luiz Hermenegildo; SILVA, Franciele Alves. Massificação cultural, práticas educativas e autonomia social. Revista Diálogo Educativo, Curitiba, v. 12, n. 37, p. 1065-1084, set./dez. 2012.

FARIA, Neice Müller Xavier; FACCHINI, Luiz Augusto; FASSA, Ana Claudia G.; TOMASI, Elaine. Processo de Produção Rural e Saúde na Serra Gaúcha: um estudo descritivo. Cadernos de Saúde Pública, Rio de Janeiro, Escola Nacional de Saúde Pública Sergio Arouca, Fundação Oswaldo Cruz, v. 16, n. 1, jan./mar. 2000. P. 115-128.

FREIRE, Paulo. Pedagogia do Oprimido. Rio de Janeiro: Paz e Terra, 1987.

FREIRE, Paulo. Pedagogia da Autonomia: saberes necessários à prática educativa. São Paulo: Paz e Terra, 1998.

FREIRE, Paulo. Pedagogia do Oprimido. Rio de Janeiro: Paz e Terra, 2008.

GHINI, Raquel; BETTIOL, Wagner. Proteção de Plantas na Agricultura Sustentável. Cadernos de Ciência \& Tecnologia, Brasília, Embrapa Informação Tecnológica, v. 17, n. 1, p. 61-70, jan./abr. 2000.

GOMIDE, Márcia. Agrotóxico que Nome Dar? Revista Ciência e Saúde Coletiva, Manguinhos, Associação Brasileira de Saúde Coletiva, v. 10, n. 4, p. 1047-1054, out./dez. 2005.

GUIVANT, Julia. Percepção dos Olericultores da Grande Florianópolis (SC) sobre os Riscos Decorrentes do uso de Agrotóxicos. Revista Brasileira de Saúde Ocupacional, São Paulo, Ministério do Trabalho, Fundacentro, v. 82, n. 22, p. 47-57, 1994.

KUGLER, Henrique. Paraíso dos Agrotóxicos. Ciência Hoje, Rio de Janeiro, n. 296, v. 50, p. 20-25, 2012.

LEROY, Jean Pierre. Prefácio. Campanha o Veneno está na Mesa. Agrotóxico: caderno de formação um, S/D. P. 1-64. Disponível em: <http://www.mst.org.br/sites/default/files/caderno\%20de\%20formacao_um.pdf>. Acesso em: 05 jan. 2013. LÓPEZ, José Luis Luján; CEREZO, José Antonio Lópes. Educación CTS en acción: enseñanza secundaria y universidad. In: GARCÍA, Martha Isabel González;

$760 \quad$ Educação \& Realidade, Porto Alegre, v. 40, n. 3, p. 745-762, jul./set. 2015. 
CEREZO, José Antonio Lópes; LÓPEZ, José Luis Luján. Ciencia, Tecnología y Sociedad: una introducción al estudio social de la ciencia y la tecnología, Madrid, Editorial Tecnos S.A., 1996. P. 225-252.

MIRANDA, Ary Carvalho de; MOREIRA, Josino Costa; CARVALHO, René de; PERES, Frederico. Neoliberalismo, Uso de Agrotóxicos e a Crise da Soberania Alimentar no Brasil. Revista Ciência e Saúde Coletiva, Manguinhos/RJ, Associação Brasileira de Pós-Graduação em Saúde Coletiva,v. 12, n. 1, p. 7-14, jan./mar. 2007. MOGENDORFF, Janine Regina. A Escola de Frankfurt e seu Legado. Revista Verso e Reverso, São Leopoldo, Unisinos, n. XXVI, v. 63, p. 152-159, 2012.

MOLINA, Mônica Castagna; SÁ, Lais Mourão. Licenciatura em Educação do Campo. In: CALDARTE, Roseli Salete; PEREIRA, Isabel Brasil; ALENTEJANO, Paulo; FRIGOTTO, Gaudêncio (Org.). Dicionário da Educação do Campo. Rio de Janeiro, São Paulo: Escola Politécnica de Saúde Joaquim Venâncio, Expressão Popular, 2012. P. 466-472.

MORAES, Roque; GALIAZZI, Maria do Carmo. Análise Textual Discursiva. Ijuí: Editora Unijuí, 2007.

MOREIRA, Josino Costa et al. Avaliação Integrada do Impacto do Uso de Agrotóxicos sobre a Saúde Humana em uma Comunidade Agrícola de Nova Friburgo/ RJ. Revista Ciência e Saúde Coletiva, Manguinhos/RJ, Associação Brasileira de Pós-Graduação em Saúde Coletiva, v. 7, n. 2, p. 299-311, 2002.

PERES, Frederico; MOREIRA, Josino Costa (Org.). É Veneno ou é Remédio? Agrotóxicos, Saúde e Ambiente. Rio de Janeiro: Fiocruz, 2003.

PINHEIRO, Nilcéia Aparecida Maciel; SILVEIRA, Rosemari Monteiro Foggiatto; BAZZO, Walter Antonio. Ciência, Tecnologia e Sociedade: a relevância do enfoque CTS para o contexto do Ensino Médio. Ciência e Educação, Bauru/SP, Programa de Pós-Graduação em Educação para a Ciência - UNESP, v. 13, n. 1, p. 71-84, 2007.

REIS, Pedro. Os Temas Controversos na Educação Ambiental. Revista Pesquisa em Educação Ambiental, São Carlos/SP, Universidade Federal de São Carlos, Universidade Estadual Paulista, Universidade de São Paulo, v. 2, n. 1, p. 125-140, jan./ jul. 2007.

RIGOTTO, Raquel Maria; ROSA, Slene Ferreira. Agrotóxicos. In: CALDARTE, Roseli Salete; PEREIRA, Isabel Brasil; ALENTEJANO, Paulo; FRIGOTTO, Gaudêncio (Org.). Dicionário da Educação do Campo. Rio de Janeiro; São Paulo: Escola Politécnica de Saúde Joaquim Venâncio; Expressão Popular, 2012. P. 86-94.

SILVA, José de Souza. Quo vadis, Tecnociência? A Emergência de uma Ciência da Sociedade no Contexto da Mudança de Época. In: SANTOS, Lucy Woellner dos et al. (Org.). Ciência, Tecnologia e Sociedade: o desafio da interação. Londrina: IAPAR, 2004. P. 275-328.

SNYDERS, Georg. Pedagogia Progressista. Lisboa: Livraria Almedina, 1974.

VEIGA, Marcelo Motta. Agrotóxicos: eficiência econômica e injustiça socioambiental. Revista Ciência e Saúde Coletiva, Manguinhos/RJ, Associação Brasileira de Pós-Graduação em Saúde Coletiva, v. 12, n. 1, jan./mar. 2007.

WHO (WORLD HEALTH ORGANIZATION). Public Health Impact of Pesticides Used in Agriculture. 1990. Disponível em: <http://whglibdoc.who.int/publications/1990/9241561394>. Acesso em: 18 jan. 2013. 
Carolina dos Santos Fernandes é licenciada em Química pela Universidade Federal do Rio Grande (FURG) mestre em Educação Científica e Tecnológica pelo Programa de Pós-Graduação em Educação Científica e Tecnológica (PPGECT) da Universidade Federal de Santa Catarina (UFSC) e doutoranda do PPGECT/ UFSC. É professora do Departamento de Metodologia de Ensino da UFSC.

E-mail: carolferquimic@hotmail.com

Geovana Mulinari Stuani é licenciada em Ciências Biológicas Mestre em Educação Científica e Tecnológica pelo Programa de Pós-Graduação em Educação Científica e Tecnológica PPGECT/UFSC. Doutoranda em Educação Científica e Tecnológica, PPGECT/UFSC. Professora da rede municipal de ensino de Chapecó/SC na área de Ciências.

E-mail: geovana.mulinari@gmail.com

Apoio: FUMDES (Fundo de apoio à Manutenção e ao Desenvolvimento da Educação Superior). 